\title{
A Crítica de Durkheim ao Epifenomenismo em Psicologia e suas Implicaçóes Sociológicas E Filosóficas ${ }^{1}$
}

\author{
Rafael Henrique Teixeira ${ }^{2}$
}

\begin{abstract}
RESUMO: O objetivo deste artigo é tomar a crítica de Durkheim ao epifenomenismo em psicologia para demonstrar o modo pelo qual sua sociologia mobiliza questóes e problemas característicos da filosofia francesa de finais do século XIX. Primeiramente, descreveremos o recurso de Durkheim a teses advindas da filosofia, visando a apontar as insuficiências da psicofisiologia na definição da vida psíquica. Nessa ocasiáo, apresentaremos a consonância do ponto de vista de Durkheim com as concepçóes de seu contemporâneo, Bergson. Em seguida, demonstraremos que não se trata para Durkheim de simplesmente duplicar as teses da filosofia. A partir de uma analogia entre a consciência individual e a consciência coletiva, Durkheim tomará um pressuposto fundamental retirado da crítica filosófica ao epifenomenismo - a saber, a autonomia e a independência relativa do espírito para com seu substrato - e o estenderá à sua concepção de sociedade. Por fim, autorizados por Durkheim, que admite que o problema da gênese do coletivo a partir do individual é um problema sociologicamente insolúvel, destinado à metafísica resolver, evidenciaremos como a filosofia espiritualista, comemorada por Durkheim como prestando grandes serviços à ciência, poderia contribuir na elucidação desse problema.
\end{abstract}

PALAVRAS-CHAVE: Sociologia. Filosofia. Memória. Indivíduo. Sociedade.

\section{INTRODUÇÃO}

Durkheim reconhece que a vida individual e a vida coletiva se constituem por meio de representaçóes. Mas essa aproximação, “[...] longe de justificar a concepção que reduz a sociologia a ser mero corolário da psicologia individual, colocará ao contrário em relevo a independência relativa desses dois mundos e dessas duas ciências." (DURKHEIM, 2010, p. 02). O que se encontra em jogo para Durkheim com esse reconhecimento é o ideal de autonomia que obseda sua sociologia. Não haveria por que apelar à necessidade de edificaçáo de uma nova ciência, com métodos que lhe são próprios, caso não tivesse sido encontrado um registro de fenômenos que exigisse, por sua

\footnotetext{
${ }^{1}$ http://dx.doi.org/10.1590/S0101-31732016000400002

${ }^{2}$ Pós-Doutorando em Filosofia/UNICAMP - Bolsista FAPESP. rafael.discord@gmail.com.
} 
natureza irredutível aos quadros de outras ciências, uma maneira adequada de acessá-los, compreendê-los e descrevê-los.

[...] separando assim a vida social da vida individual, náo pretendemos de modo algum dizer que ela nada tem de psíquico. Ao contrário, é evidente que ela é essencialmente constituída de representaçóes. Apenas, as representaçóes coletivas têm natureza totalmente diferente daquelas do indivíduo. Não vemos nenhum inconveniente em dizer que a sociologia é uma psicologia, desde que tenhamos o cuidado de acrescentar que a psicologia social tem suas leis próprias, que não são as da sociologia. (DURKHEIM, 2011, p. 401).

Além de uma natureza representacional aproximar as duas ordens de realidade, a sociedade apenas pode se realizar através das consciências individuais. Mas nem por isso as representaçóes coletivas deixam de constituir um mundo à parte e, enquanto tal, de possuir leis que são irredutíveis à sua manifestação nos limites da consciência individual. Os fatos sociais são maneiras de agir, pensar e sentir "[...] exteriores ao indivíduo, e dotados de um poder de coerção em virtude do qual se impõem a eles." Eles não se confundem com os fenômenos psíquicos, afirma Durkheim (2007a, p. 05), "[...] os quais apenas possuem existência na consciência individual e por meio dela”. É fato social "[...] toda maneira de fazer, fixada ou não, susceptivel de exercer sobre o indivíduo uma coerção exterior." (DURKHEIM, 2007a, p. 14, grifo do autor). Essa exterioridade, pela pressão que exerce sobre as consciências individuais, basta para demonstrar que o fato social não é mera duplicata do que nelas se passa, e que, consequentemente, "[...] a sociologia não é um corolário da psicologia.” (DURKHEIM, 2007a, p. 101).

Não é nosso objetivo aqui retraçar em filigrana as operaçôes epistemológicas da sociologia de Durkheim, ligadas ao reconhecimento da necessidade de uma nova ciência para o trato de um fenômeno irredutível aos quadros da psicologia, tampouco um exame detido da natureza coercitiva do fato social na qualidade de índice de uma realidade psíquica que é exterior ao indivíduo. Pretendemos simplesmente tomar um aspecto preciso mobilizado por Durkheim e retirar dele alguns desenvolvimentos: trata-se da crítica à psicofisiologia ou concepção epifenomenista da vida do espírito individual. Veremos que, a despeito da necessidade de autonomização da ciência dos fatos sociais com relação à psicologia, a própria fundamentação da irredutibilidade do social ao psíquico não apenas é tributária de uma concepção em torno 
da natureza do espírito individual como, nessa concepção que supomos cara à sociologia durkheimiana, encontramos uma mobilização de teses que se ligam estreitamente ao cenário filosófico francês de finais do século XIX. Sem de modo algum colocar em xeque o ideal de autonomização que anima a sociologia durkheimiana, nosso objetivo é demonstrar que a edificação de um saber sociológico que se pretendeu autônomo não pôde se operar sem que ele fosse maculado por reflexôes vindas de outras áreas do saber, da psicologia e da filosofia.

Primeiramente, observaremos um Durkheim em absoluta consonância com a filosofia praticada em território francês, no momento da eclosão de sua sociologia. Para sublinhar essa proximidade, utilizaremos algumas teses de Bergson. Em seguida, passaremos à análise do sentido preciso que Durkheim confere ao reconhecimento da validade da crítica da filosofia espiritualista ao epifenomenismo em psicologia: a demonstração da irredutibilidade da vida do espírito individual ao seu substrato neurofisiológico servirá à Durkheim para apontar a irredutibilidade da consciência coletiva ao espírito individual. Por fim, munidos das assinaláveis analogias que Durkheim apresenta com o pensamento de Bergson, levantaremos algumas hipóteses em torno de algo que o próprio Durkheim assumiu como sendo da alçada da metafísica resolver, e não da sociologia: o problema da gênese da consciência coletiva.

O recurso de Durkheim à crítica espiritualista ao epifenomenismo em psicologia mobiliza elementos de grande alcance, os quais vão muito além de uma mera partilha metodológica e ontológica entre psicologia e sociologia, indivíduo e sociedade. Nesse ponto preciso da doutrina durkheimiana, é possível observar algo que Bergson reconheceu com precisão. Com a ideia de representaçóes coletivas, Durkheim nos conduz "[...] em vias autenticamente metafísicas." (BERGSON, 2011a, p. 466). Fato notório, se levarmos em consideração todo o esforço durkheimiano em afirmar que seu método e sua ciência se pretendem independentes "[...] de toda filosofia." (DURKHEIM, 2007a, p. 139).

\section{A CRÍTICA BERGSONIANA E DURKHEIMIANA AO EPIFENOMENISMO EM PSICOLOGIA}

Durkheim toma de empréstimo da filosofia certa crítica realizada à concepção da vida psíquica como epifenômeno da atividade orgânica ou física, apresentada como o "grande serviço prestado à ciência" pelos filósofos 
espiritualistas $^{3}$, os quais combateram "[...] as doutrinas que reduzem a vida psíquica a não ser outra coisa senão a eflorescência da vida física." (DURKHEIM, 2007b, p. 340). No início dos anos 1870, a psicologia francesa permanecia ainda anexada a uma filosofia de inspiração espiritualista. E foi precisamente contra essa dependência que nasceu a corrente da qual Taine foi a referência e Ribot seu principal animador (MUCCHIELLI, 1994). Para Ribot, a psicologia deve se ocupar das condiçôes orgânicas da personalidade, pois "[...] é nos fenômenos os mais elementares da vida que é preciso buscar os elementos da personalidade; são eles que lhes dão sua marca própria, seu caráter," (RIBOT, 1883 , p. 620). Ou, como diria seu precursor Taine (1870, p. 07), "[...] um fluxo de vibrações nervosas, eis o espírito."

A despeito dos progressos realizados pela psicofisiologia, admite Durkheim (2007b, p. 340), ela está condenada a representar apenas uma fração ínfima dos fenômenos psíquicos, na exata medida em que o que lhes é essencial “[...] não deriva de causas orgânicas.” E Durkheim não se exime de reconhecer verdadeiro débito para com o espiritualismo que se volta contra as teses da psicofisiologia: "[...] a essência do espiritualismo não se encontraria na ideia que os fenômenos psíquicos não podem ser imediatamente derivados dos fenômenos orgânicos? Ora, nosso método apenas é em parte uma aplicação desse princípio aos fatos sociais." (DURKHEIM, 2007a, p. VII).

Antes de verificar o sentido preciso dessa aplicação pleiteada por Durkheim, vejamos a maneira pela qual a postura durkheimiana em torno da vida do espírito apresenta analogias consideráveis com os desenvolvimentos de Bergson acerca de semelhante temática. A hipótese epifenomenista, segundo Bergson, afirma que os estados cerebrais criam a representaçâo. Isso implica reconhecer que "[...] a um estado cerebral determinado corresponde um estado de consciência determinado", de modo que os movimentos interiores da massa cerebral forneceriam àquele que soubesse decifrá-los "[...] o detalhe completo do que se passa em uma consciência correspondente” (BERGSON, 2008a, p. 202).

Representemo-nos movimentos moleculares realizando-se no cérebro; a consciência se desprenderia deles às vezes sem que se saiba como, e

\footnotetext{
${ }^{3}$ Não entraremos aqui no debate em torno do estatuto do epíteto espiritualista que, na história da filosofia e das ciências em território francês, se prestou a inúmeras interpretaçóes e definiçôes nem sempre idênticas. No mais, tal como o qualificativo vitalista em biologia, o qualificativo espiritualista, sobretudo em se tratando das ciências positivas, é geralmente acompanhado de uma acusação ou depreciação. Tomemos por espiritualismo simplesmente uma doutrina que admite, ao lado da matéria e da jurisdição de suas leis, um princípio que é da ordem do espírito (pensamento, consciência, memória etc.) e cujo funcionamento é irredutível a quadros estritamente orgânicos e materiais.
} 
iluminaria seu traço ao modo de uma fosforescência [...]. Mas a qualquer imagem que nos reportemos não demonstramos, não demonstraremos nunca, que o fato psicológico seja determinado necessariamente pelo movimento molecular. Pois em um movimento encontramos a razáo de outro movimento, mas não daquele de um estado de consciência: somente a experiência poderá estabelecer que este último acompanha o outro. (BERGSON, 2007, p. 111).

$\mathrm{Na}$ contramão das reduções da psicofisiologia, Bergson erigirá uma doutrina que visa a estabelecer uma nova relação entre o cérebro e a consciência. Não se trata de retirar o espírito da matéria, suspendê-lo em um mundo inteligível e sem comunicação com a realidade neurológica e sensóriomotora: o que significaria cair no arbitrário do "antigo espiritualismo", o qual se limitava a "[...] considerar os termos extremos" e a declarar que "[...] o espírito é irredutível à matéria.” (BERGSON, 2011b, p. 246). Trata-se de precisar a relação entre espírito (fato psicológico) e matéria (substrato cerebral). Nossa vida interior "[...] é algo como uma frase única, esboçada desde o primeiro despertar da consciência”, de modo que nosso passado se encontra a todo o momento inteiramente presente, mas "subconsciente" (BERGSON, 2008b, p. 57). Nesse cenário, no qual o espírito é memória, o papel do cérebro é "[...] extrair da consciência tudo o que é utilizável para a ação". O cérebro não produz automaticamente representaçóes, tampouco conserva o passado. Seu papel é simplesmente deixar transparecer o que é praticamente útil em uma situação presente, deixando o restante nas sombras da inconsciência. Uma representação tem sua origem em uma ação presente informada por lembranças que se atualizam, em uma passagem do inconsciente mnemônico a um consciente presente que se liga a uma ação útil.

[...] tal é o papel do cérebro frente ao espírito em geral. Retirando do espírito o que é exteriorizável em movimento, inserindo o espírito no quadro motor, ele o conduz o mais das vezes a limitar sua visão, mas também a tornar sua ação eficaz. Quer dizer que o espírito excede o cérebro por todos os lados, e que a atividade cerebral apenas corresponde a uma ínfima parte da atividade mental. (BERGSON, 2008b, p. 57). 
Encontramos em Durkheim argumentos que sugerem uma consonância com a alternativa bergsoniana ao epifenomenismo ${ }^{4}$. Durkheim (2010, p. 17) toma o espírito como "um curso contínuo de representaçôes" que se penetram mutuamente e que se conservam independentemente do cérebro que lhes serve de substrato. Se as representaçóes morressem assim que elas nascessem, pergunta-se Durkheim (2010, p. 25), “[...] do que poderia ser feito o espírito? É preciso escolher: ou bem o epifenomenismo é verdadeiro, ou bem há uma memória propriamente mental". A única maneira de escapar à psicologia epifenomenista é "[...] admitir que as representaçôes sejam susceptíveis de persistir enquanto representaçóes”. Os fatores psíquicos de nossa conduta não dependem exclusivamente de causas físicas ou orgânicas. $\mathrm{O}$ que dirige nossas açôes não são apenas ideias que ocupam a ação presente, ligadas a excitaçôes e abalos neuronais, mas “[...] todos os resíduos deixados por nossa vida anterior", ou seja, "[...] tudo o que constitui nosso caráter moral" (DURKHEIM, 2010, p. 08), ao qual Bergson, por seu lado, dá o nome de personalidade. É nossa personalidade inteira, que compreende "[...] a totalidade de nossas lembranças” (BERGSON, 2008c, p. 184), que participa de nossa percepção e ação presentes.

O epifenomenismo concebe que uma representação apenas pode ser evocada por meio de um estado físico antecedente. Se as representaçóes apenas existem na medida em que os elementos nervosos que a suportam se encontram em condiçôes determinadas, enfatiza Durkheim (2010), e se ela desaparece a partir do momento em que essas condiçóes não se realizam, seríamos obrigados a reconhecer que a representação não tem realidade própria, tampouco que ela se conserva: em suma, que ela não possui outra realidade senão aquela que ela detinha de seu substrato e da causa correspondente de sua excitação. Quando, nessas condições, se deseja compreender os fenômenos mentais, o modo como eles se produzem, reproduzem e se modificam, não é a eles que a psicologia epifenomenista se volta, conclui Durkheim, mas aos fenômenos anatômicos

\footnotetext{
${ }^{4}$ Consonância observável em Représentations individuelles et représentations collectives, ensaio publicado por Durkheim, em 1898, na Revue de méthaphysique et de morale - ou seja, dois anos após a publicação de Matière et mémoire. Náo encontramos o nome de Bergson no referido texto durkheimiano. Mas observamos, em contrapartida, a persistência de um mesmo problema (a relação do espírito com seu substrato), de uma solução que mobiliza termos semelhantes (autonomia e independência relativas) e uma passagem decisiva pelo problema da memória, de modo que, se a ausência de uma referência explícita nos impede de falar em termos de uma influência de Bergson sobre Durkheim, o que seria forçoso de nosso ponto de vista, as persistências supracitadas, aliadas à confissão durkheimiana dos serviços prestados à ciência dos fatos sociais por uma filosofia de orientação espiritualista, autorizam o desenvolvimento da comparação aqui pleiteada.
} 
dos quais se pretende que eles sejam a imagem mais ou menos fiel. A esse modo de encarar a vida mental se oporá a tese que Durkheim compactua com Bergson: a memória, o tecido de nossas representações, "[...] não é um fato puramente físico", pois as representaçóes podem se conservar "enquanto tais" (DURKHEIM, 2010, p. 20).

Não que nossa atividade intelectual consista exclusivamente em reproduzir sem mudanças os estados de consciência anteriormente experimentados. Mas para que eles possam ser submetidos a uma elaboração verdadeiramente intelectual, diferente, consequentemente, daquelas que implicam as puras leis da matéria viva, seria ainda preciso que eles tivessem uma existência relativamente independente de seu substrato material (DURKHEIM, 2010, p. 13).

Como Bergson, não se trata simplesmente de aceitar essa conservação em si das lembranças e sua independência para com o cérebro. Ao lado dessa independência, Durkheim reconhece uma elaboração que denomina intelectual, e que toma como material as representaçóes armazenadas pela memória. Não encontraremos em Durkheim uma precisão em torno dessa elaboração, tampouco, como no caso de Bergson, uma fundamentação desse processo de atualização de lembranças, a partir de um critério de utilidade para com uma situação presente. Mas não vemos nenhum contrassenso, pela natureza da vida representativa que nos apresenta Durkheim, em reconhecer com Bergson (2008d, p. 176, grifo do autor) que o trabalho intelectual se apresenta como um movimento do espírito que consiste "[...] em conduzir uma mesma representação através de planos de consciência diferentes em uma direção que vai do abstrato ao concreto", que vai do tecido contínuo das lembranças a uma ação presente, pois Durkheim, como Bergson, não isola a atividade do espírito de exigências corporais.

Para reconhecer ao espírito essa autonomia limitada que é, no fundo, tudo o que contém de essencial e de positivo nossa noçáo de espiritualidade, não é necessário imaginar uma alma separada de seu corpo e levando em não sei qual meio ideal uma existência sonhadora e solitária. A alma se encontra no mundo; ela mistura sua vida àquela das coisas e podemos dizer, caso queiramos, de todos os nossos pensamentos, que eles se encontram no cérebro. É somente preciso acrescentar que, no interior do cérebro, eles não são localizáveis a rigor, que eles sequer são nele situados em pontos definidos mesmo que eles se encontrem mais em relação com algumas regiôes do que com outras. Sozinha, essa difusão basta para provar que eles são algo de específico; pois, porque eles são assim difusos, é preciso de toda necessidade que seu modo de composição não seja aquele da massa 
cerebral e que, consequentemente, eles tenham uma maneira de ser que lhes é especial. (DURKHEIM, 2010, p. 39).

Há aqui uma particularidade. Ao passo que Bergson dedicará longas páginas à demonstração do papel do cérebro e do corpo (sensaçôes e movimentos) na orientação "da memória para o real", ligando-a assim ao presente sem deixar de admitir sua independência para com a matéria (BERGSON, 2008c, p. 198), Durkheim se limita a afastar a tese epifenomenista de uma dependência estrita independentemente da natureza funcional da ligação entre alma e corpo: se o pensamento, em algum momento, tem uma ligação com seu substrato cerebral, é simplesmente seu aspecto difuso e não localizável nele que permite reconhecer-lhe um modo de ser especial. Seja como for, em ambos os casos encontramos a demonstração da irredutibilidade do espírito à suas determinaçôes orgânicas e físicas, bem como a admissão de uma autonomia relativa do espírito tomado como tecido de representaçóes armazenadas em uma memória incorporal.

Por fim, não se trata, para Durkheim, com seu recurso a uma concepção do espírito tão próxima das teses de seu contemporâneo, Bergson, de confirmar tal concepção pura e simplesmente. Não podemos nos esquecer de que esse recurso se localiza no interior de um objetivo preciso: demonstrar, a partir das analogias da vida do espírito individual com o espírito coletivo, a maneira pela qual este se distingue qualitativamente do primeiro. Durkheim pretende fundar uma ciência dos fatos sociais, não reformular a psicologia, demonstrando o valor de teses que encontra em uma filosofia de orientação espiritualista, tampouco esboçar uma nova hipótese acerca das relaçôes entre alma e corpo, espírito e matéria, pano de fundo essencial das reflexôes de Matière et mémoire 5 .

\footnotetext{
${ }^{5}$ Razão pela qual Durkheim, distintamente de Bergson, não se ocupa das hipóteses que a história da filosofia oferece acerca da relação entre alma e corpo. O epifenomenismo da psicologia não é, para Bergson, um fenômeno gratuito. A ciência recebeu algo da filosofia, e a única hipótese que "[...] a metafísica dos três últimos séculos nos legou sobre esse ponto é justamente aquela de um paralelismo rigoroso entre a alma e o corpo, a alma exprimindo certos estados do corpo, ou o corpo exprimindo a alma, ou a alma e o corpo sendo duas traduçôes, em línguas diferentes, de um original que não seria nem um nem outro: nos três casos, o cerebral equivaleria exatamente ao mental." (BERGSON, 2008b, p. 39). Quando a filosofia "[...] pretende apoiar essa tese paralelista sobre os dados da ciência" ela comete um "círculo vicioso": se a ciência interpreta a solidariedade entre as séries psicológica e fisiológica, "[...] que é um fato, no sentido do paralelismo, que é uma hipótese (e uma hipótese muito pouco inteligível), é, consciente ou inconscientemente, por razôes de ordem filosófica. É porque ela foi habituada por certa filosofia a acreditar que não há hipótese mais plausível, mais conforme aos interesses da ciência positiva," (BERGSON, 2008c, p. 05). Há uma metafísica subjacente à psicofisiologia. Do ponto de vista bergsoniano, “[...] a hipótese de um paralelismo psicofisiológico é
} 


\section{A SIGNIFICAÇÁO SOCIOLÓGICA DA CRÍTICA AO EPIFENOMENISMO}

O objetivo de Durkheim com sua crítica ao epifenomenismo em psicologia é assim anunciado: “Trata-se simplesmente de introduzir e de aclimatar em sociologia uma concepção paralela àquela que tende cada vez mais a prevalecer em psicologia," (DURKHEIM, 2010, p. 45). Objetivo um tanto quanto surpreendente, se levarmos em consideração um imperativo essencial dessa mesma sociologia: distingui-la da "psicologia individual" (DURKHEIM, 2010, p. 45). Ou seja, a necessidade de emancipação da sociologia com relação à psicologia não pode dispensar absolutamente o recurso a uma concepção da vida do espírito individual, cujo pressuposto, sua autonomia relativa com relação ao seu substrato, será decisivo para a definição da sociedade pleiteada pela sociologia.

Ora, quando dissemos alhures que os fatos sociais são, em certo sentido, independentes dos indivíduos e exteriores às consciências individuais, apenas afirmamos do reino social o que acabamos de estabelecer a propósito do reino psíquico. A sociedade tem por substrato o conjunto dos indivíduos associados. O sistema que eles formam ao se unirem [...] constitui a base sobre a qual se eleva a vida social. As representaçóes que são sua trama se deduzem das relaçôes que se estabelecem entre os indivíduos assim combinados [...]. Ora, se não vemos nada de extraordinário no fato de que as representaçôes individuais, produzidas pelas açóes e reaçôes mantidas entre os elementos nervosos, não sejam inerentes a esses elementos, o que haveria de surpreendente no fato de que as representaçóes coletivas, produzidas pelas açōes e as reaçôes mantidas entre as consciências elementares das quais é feita a sociedade, não deriva diretamente destas últimas e, consequentemente, as excedem? A relação que, na concepção, une o substrato social à vida social, é absolutamente análoga àquela que devemos admitir entre o substrato fisiológico e a vida psíquica dos indivíduos, caso não queiramos negar toda psicologia propriamente dita. (DURKHEIM, 2010, p. 34).

A intenção de Durkheim é facilmente verificável: assumir uma analogia dos fatos sociais e psíquicos, para estender alguns princípios retirados de uma concepção em torno da vida do espírito individual ao trato do

uma doutrina que nasce com Descartes", que toma "sua forma coerente com Espinosa e Leibniz" e que é, em seguida, empobrecida, ao adotar "[...] a forma atual do epifenomenismo", (RIQUIER, 2009, p. 317). A hipótese paralelista serve para a explicação de fatos relativos à solidariedade entre a alma e o corpo, mas ela não é retirada propriamente desses fatos: ela simplesmente fornece "ao materialismo atual” a segurança que ele "acredita” encontrar em "fatos novos." (RIQUIER, 2009, p. 317). 
fenômeno social. Essa apropriação de princípios que se ligam à crítica ao epifenomenismo em psicologia deve ser lida na chave de uma usurpação de seu sentido originário. Trata-se de uma apropriação não propriamente dos resultados de certa psicologia ou filosofia de orientação espiritualista, mas de seus pressupostos fundamentais, aplicados, nesse ponto, a uma nova ordem de fenômenos da vida do espírito, não mais individual, mas coletiva, e que não se deixa reduzir completamente aos quadros da primeira. Afinal, os atributos que constituem a vida psíquica se encontram na sociedade, porém, "[...] elevados a uma potência muito mais elevada e de modo a constituir algo de inteiramente novo." (DURKHEIM, 2010, p. 48). Da constatação da natureza sui generis do espírito individual, tecido de representaçóes conservadas pela memória e irredutíveis ao seu substrato neurofisiológico no qual, não obstante, elas se atualizam, Durkheim retira uma tese fundamental para a caracterização da consciência coletiva em sua relação com os fenômenos que lhe são imediatamente inferiores.

O conjunto das crenças e dos sentimentos comuns à média dos membros de uma sociedade forma um sistema determinado que tem sua vida própria; podemos chamá-lo a consciência coletiva ou comum. Sem dúvida, ela não tem por substrato um órgão único; ela é, por definição, difundida em toda a extensão da sociedade; mas ela náo deixa de possuir características específicas que fazem dela uma realidade distinta. Com efeito, ela é independente das condiçôes particulares em que os indivíduos se encontram colocados [...]. Ela é outra coisa então que as consciências particulares, ainda que ela apenas se realize nos indivíduos. Ela é o tipo psíquico da sociedade, tipo que possui suas propriedades, suas condiçōes de existência, seu modo de desenvolvimento, tal como os tipos individuais, ainda que de outra maneira. (DURKHEIM, 2007b, p. 46).

É a sociedade "[...] que pensa, que sente, que deseja, ainda que ela apenas possa querer, sentir ou agir por intermédio das consciências particulares” (DURKHEIM, 2010, p. 36). Psíquicos de alguma maneira, pois modos de pensar e de agir, os "estados de consciência coletiva" são de outra natureza, qualitativamente distintos dos estados de consciência individuais. Contudo, a sociedade não pode negligenciar os indivíduos. Ela apenas pode se realizar através deles. Ela então penetra nas consciências individuais, acrescentando ao "[...] nosso ser individual um ser psíquico de um gênero novo" (DURKHEIM, 2007a, p. XV). Mas, dotada de uma ubiquidade que a libera das determinaçóes restritas de seu substrato, a vida coletiva não pode ser dita como residindo nele. Sua razão de ser não se encontra nele, da mesma 
maneira que a razão de ser da consciência individual não se encontra nos movimentos do tecido cerebral.

A sociedade é, portanto, ao mesmo tempo dependente e distinta do conjunto de indivíduos que a compóem. Do mesmo modo que o espírito individual, memória ou tecido contínuo de representaçóes que possui um corpo que lhe faz tomar pé na realidade, ela náo se apoia sobre o vazio. Mas, afirma Durkheim (2010, p. 43), ela vive "uma vida própria". A sociedade constitui um mundo à parte, irredutível em sua essência ao que lhe precede, entretanto, ao mesmo tempo, tributário de sua existência para o pleno desenvolvimento de sua própria irredutibilidade. Afinal, “[...] não há reino da natureza que não se ligue a outros reinos", de modo que seria absurdo tomar tanto a vida psíquica quanto a vida social como um absoluto "que não se ligaria ao restante do universo." (DURKHEIM, 2010, p. 32). Mas seria igualmente absurdo afirmar que essas duas dimensóes da vida do espírito se definem pura e simplesmente a partir da ordem de fenômenos imediatamente inferior no qual elas se desenvolvem: de um lado, a matéria nervosa, de outro, a somatória das consciências individuais que constitui a matéria de uma sociedade. Se a consciência individual não é, para Durkheim, simples epifenômeno da atividade neurofisiológica, da mesma maneira, a consciência coletiva não é simples epifenômeno da associação das individualidades que entram em sua composição.

Podemos concluir que o recurso de Durkheim a pressupostos essenciais de uma psicologia ou filosofia de orientação espiritualista é condição fundamental para que seja admitida a irredutibilidade e autonomia relativa do social com relação ao psíquico. Levantaremos, na sequência, algumas hipóteses em torno do problema da gênese da consciência coletiva na sociologia durkheimiana. Para lançar alguma luz em torno desse problema, nós nos apoiaremos sobre postulados que encontramos na filosofia de Bergson. E dois elementos nos autorizam a essa tentativa. Primeiramente, as semelhanças que encontramos entre Durkheim e Bergson, em se tratando da crítica ao epifenomenismo em psicologia. Em segundo lugar, o reconhecimento do próprio Durkheim dos limites da sociologia na elucidação da síntese do individual que preside à gênese do coletivo e, sobretudo, a saída que ele aponta, uma vez reconhecidos esses limites.

\section{Os LIMITES DA SOCIOLOGIA NA DESCRIÇÃo DA GÊNESE DA CONSCIÊNCIA COLETIVA}

A consciência coletiva não se apoia sobre o vazio. Como a consciência individual, a qual se liga a um corpo e a mecanismos neurofisiológicos, ela possui 
um substrato: no caso, uma série de consciências elementares que contribuem em sua fomentação. No mais, como a consciência individual, ela não se reduz a uma mera duplicata dos elementos que compóem seu substrato. Os estados de consciência privados apenas se tornam sociais na medida em que "[...] se combinam sob a ação das forças sui generis que desenvolve a associação", de sorte que, "[...] na sequência dessas combinaçóes e alteraçôes mútuas que dela resultam, elas se tornam outra coisa." (DURKHEIM, 2010, p. 36). Durkheim não entra em detalhes em torno desse processo, responsável pela elevação de estados de consciência individuais ao estatuto de representaçóes coletivas que desenvolvem uma vida própria. Ele se limita a afirmar que se trata de uma síntese sui generis, e que essa síntese introduz uma diferença da ordem da qualidade entre os elementos que entram em sua composição e a resultante de sua fusão.

De acordo com Durkheim, na medida em que o psíquico e o coletivo se encontram em estreita relaçáo, o modo de ser do primeiro pode, ao menos, "facilitar a explicaçáo" do segundo (2007a, p. 110). Os fatos sociais são produzidos "[...] por uma elaboração sui generis de fatos psíquicos", e essa elaboração "[...] não é sem analogias com aquela que se produz em cada consciência individual” (2007a, p. 110): síntese de sensaçóes, reflexos e instintos na origem da qual se encontra a espiritualidade autônoma e irredutível a esses elementos que, contudo, entram em sua composição. A psicologia, conclui Durkheim (2007a, p. 110), “[...] constitui então para o sociólogo uma propedêutica necessária." Nada de estranho nessa afirmação, caso remontemos ao que foi dito acerca do valor de uma psicologia capaz de levar em conta os limites do epifenomenismo. No entanto, desse recurso possível à psicologia Durkheim retira uma consequência radical, quando se trata de explicar não simplesmente a relação entre duas ordens de fenômenos (orgânico e psíquico, psíquico e social), mas a passagem de uma ordem à outra, a gênese do estrato superior a partir do inferior: a necessidade de uma metafísica.

A vida representativa individual náo pode ser repartida entre os diversos elementos que entram em sua composição. Ela apenas pode existir no todo formado por essa reuniáo. Da mesma maneira, a vida coletiva apenas existe no todo formado pela reunião dos indivíduos, ainda que, igualmente, ela não possa ser localizada nos indivíduos que colaboram em sua formação, tampouco em uma associação sem transformação, que faria do efeito uma somatória dos elementos que entram em sua configuração. E Durkheim recorrerá agora não a uma analogia entre a natureza das relaçóes observáveis entre séries de 
fenômenos que se ligam sem se deixarem reduzir um ao outro (cérebro e consciência no plano individual, consciência individual e consciência coletiva no plano social), mas entre uma insuficiência da psicologia e da sociologia em dar conta de uma síntese, na qual os elementos que entram no processo de constituição da resultante "[...] são transformados pelo simples fato de sua fusão." (DURKHEIM, 2010, p. 37).

Sem dúvida, ignoramos como movimentos podem, combinando-se, dar nascimento a uma representaçáo. Mas náo sabemos mais como um movimento de transferência pode, quando ele é detido, se transformar em calor ou reciprocamente. Contudo, não colocamos em dúvida a realidade dessa transformação; o que é então que a primeira tem de mais impossível? Mais geralmente, se a objeção fosse válida, é toda mudança que é preciso negar; pois entre um efeito e suas causas, uma resultante e seus elementos, há sempre uma distância. É tarefa da metafísica encontrar uma concepção que torne essa heterogeneidade representável; para nós, basta que sua existência não possa ser contestada. (DURKHEIM, 2010, p. 38).

Ao reconhecer uma analogia entre os fatos mentais coletivos e individuais, Durkheim retirou uma consequência de suma importância, verdadeiramente fundante para sua sociologia: a admissão de que a consciência coletiva é irredutível e apenas parcialmente dependente do substrato por sobre o qual ela se apoia. Todavia, em se tratando do problema da síntese na origem da qual encontramos a consciência coletiva, Durkheim não se limita a reconhecer uma analogia entre os fatos psíquicos e coletivos. Ele admite, em psicologia e em sociologia, uma mesma lacuna explicativa, a qual deve ser suprimida pela metafísica. À sociologia apenas cabe aceitar um fato tomado como incontestável, a síntese transformadora que torna o efeito irredutível a suas causas. A causalidade criadora, a qual estabelece essa distância qualitativa entre causa e efeito, a natureza particular da síntese que produz os fenômenos coletivos, Durkheim não toma como objeto passível de explicação científica (FEDI, 2004). Durkheim se limita a apresentar algumas analogias com outras ordens de realidade que servem simplesmente para confirmar a tese da irredutibilidade entre efeito e causa, entre totalidade e partes constituintes, mas não para iluminar as operaçóes da síntese criadora que se encontram na origem dos fenômenos sociais. Por exemplo: a célula viva apenas contém partículas minerais, mas "[...] é impossível que os fenômenos característicos da vida residam nos átomos de hidrogênio, oxigênio, de carbono e de azoto." (DURKHEIM, 2007a, p. XIV). 
Uma breve observação. A preocupação com a natureza das relaçôes e transformaçóes que se operam entre as distintas ordens de fenômenos (material, orgânico, psíquico, social) é traço característico da filosofia francesa do século XIX. Encontramos sua expressão, por exemplo, na filosofia de Boutroux, figura importante do meio universitário no qual se deu a formação de Durkheim. Boutroux (1895, p. 134) se pergunta: "É o princípio inferior que determina a aparição do superior; ou então seria o princípio superior ele próprio que, realizando-se, suscita as condiçóes de sua realização?” Boutroux prefere a segunda opção. $\mathrm{O}$ registro de fenômeno inferior não pode determinar a aparição do superior, o segundo não é o resultado de uma mera complicação do primeiro, uma tradução em outra língua de suas leis. $\mathrm{O}$ andar inferior é apenas "[...] o estribo do princípio superior" (BOUTROUX, 1895, p. 134). De modo análogo ao que Durkheim reconhece na relação entre o psíquico e o orgânico e entre o social e o psíquico, Boutroux afirma que cada mundo "[...] possui, com relaçáo aos mundos inferiores, certo grau de independência." (BOUTROUX, 1895, p. 134).

A constatação de uma heterogeneidade entre ordens de realidade comunicáveis, porém autônomas e irredutíveis ao solo do qual se originam, é o suficiente para o cientista dos fatos sociais. Com ela se justifica a necessidade de uma ciência autônoma para o exame de um registro de fenômenos que, se não absolutamente autônomo, é ao menos irredutível em sua essência às ordens inferiores sobre as quais ele se apoia. Acerca da metafísica necessária para esclarecer a dimensão genética dos fatos sociais, inacessível ao olhar do cientista, Durkheim nada diz. Resta-nos então elencar algumas hipóteses em torno desse recurso que, tomado como necessário, não foi levado a cabo por Durkheim.

Durkheim afirmou que, "[...] se chamamos espiritualidade a propriedade distintiva da vida representativa do espírito, deveremos dizer da vida social que ela se define por uma hiperespiritualidade." (2010, p. 48, grifo do autor), pois os atributos essenciais da vida do espírito nela se encontram presentes. O que define a espiritualidade é um tecido contínuo de representaçóes cuja natureza mnemônica lhes permite sobreviver independentemente do substrato cerebral. Demonstramos de que maneira esse modo pelo qual Durkheim encara a vida psíquica se aproxima da filosofia bergsoniana. Enfatizamos que Durkheim admite que esse modo de encarar os fatos psíquicos tem o mérito de prestar grande serviço à psicologia e à sociologia, pelo reconhecimento dos limites das reduções epifenomenistas. Não teríamos motivo, por conseguinte, quando 
se trata de pensar a passagem da espiritualidade à hiperespiritualidade, para buscar em Bergson elementos que permitam sua elucidação?

Não se tratará, como feito anteriormente, de assinalar as semelhanças que os pontos de vista de Durkheim e de Bergson apresentam em torno da vida do espírito, mas de verificar em que medida a filosofia de Bergson pode suprir a necessidade, assumida por Durkheim, de uma metafísica capaz de elucidar o caráter criador da síntese do individual que se torna coletivo. Ora, se temos razão em reconhecer em Bergson um representante do espiritualismo comemorado por Durkheim, o que faremos, neste ponto, é extrapolar os serviços prestados à psicologia e à sociologia por uma concepçáo espiritualista dos fatos psíquicos. Tentaremos, através dela, elucidar a natureza da síntese que preside à passagem do individual ao coletivo.

Bergson chamou a atenção para a necessidade em conceber a conservação do passado à revelia dos elementos neurofisiológicos. "Concebemos que fenômenos físico-químicos tenham lugar no cérebro, que o cérebro esteja no corpo, o corpo no ar que lhe banha, etc.; mas o passado, uma vez realizado, se ele se conserva, onde ele se encontra?” (BERGSON, 2008c, p. 165). Em lugar algum, dirá Bergson (2008c, p. 167), pois uma sobrevivência “[...] em si do passado se impóe.” A memória, por uma síntese sui generis, “[...] retém e alinha na sequência uns dos outros todos os nossos estados na medida em que eles se produzem." (BERGSON, 2008c, p. 168).

A memória [...] não é uma faculdade de classificar as lembranças em uma gaveta ou de lhes inscrever sobre um registro. Não há registro, não há gaveta, não há sequer aqui, propriamente falando, uma faculdade, pois uma faculdade se exerce de modo intermitente, quando ela quer ou quando ela pode, ao passo que o amontoamento do passado sobre o passado prossegue sem trégua. $\mathrm{Na}$ realidade o passado se conserva a si próprio, automaticamente. (BERGSON, 2008e, p. 05).

O que Durkheim admitiu, mas abriu mão de explicar, uma síntese que toma uma multiplicidade de consciências individuais e obtém como resultado uma unidade irredutível às partes de que provém, uma consciência coletiva, Bergson explica sem dificuldades, em se tratando da relação entre as percepçôes presentes e sua conservação na qualidade de lembranças. A duração dos estados de consciência é inseparável de um ato de conservação, síntese imanente do passado com o presente. Por meio dela, passa-se, afirma Worms (2004, p. 156), de nossa vida "que se torna lembrança" a cada momento à 
"individualidade global da nossa própria vida". A síntese se opera entre o acontecimento presente e a continuidade indivisível de nosso caráter, o qual, na qualidade de memória, se transforma ao alinhar esse novo presente na continuidade indivisível que se prolonga ao avançar no tempo. Essa síntese é criadora, na medida em que, ao mesmo tempo em que a totalidade de nossos estados passados é mobilizada para informar uma situação presente, esta é, ela própria, uma vez tornada lembrança, alinhada junto a essa totalidade, de modo a fazer dela outra coisa do que era no instante imediatamente anterior. A progressão de uma personalidade no tempo é, portanto, uma continuidade ininterrupta de mudança (BERGSON, 2008c).

Talvez não possamos afirmar que a gênese da consciência coletiva durkheimiana opera de forma absolutamente análoga à edificação progressiva do caráter bergsoniano. Ao passo que, no caso da memória bergsoniana, o presente se reveza com o passado na tessitura da indivisibilidade móvel da personalidade, essencialmente aberta a cada novo presente que se torna passado em uma criaçáo continuada de si por si, no caso da consciência coletiva durkheimiana, pelo caráter coercitivo pelo qual ela se impóe e informa as consciências individuais, não seria possível admitir uma mesma criação continuada do todo pelas partes. A síntese representada pela consciência coletiva durkheimiana não poderia guardar a mesma dinâmica e abertura que guarda a personalidade bergsoniana. Todavia, a consciência coletiva não é uma forma impassível, eterna e imutável. Afirmar que ela se impóe às consciências individuais do exterior é coisa distinta de afirmar que ela está dada para todo o sempre, que ela não possui uma origem em um ato, o qual, como a memória bergsoniana, é ao mesmo tempo criador e conservador.

Para que exista fato social, "[...] é preciso que muitos indivíduos tenham misturado sua ação e que dessa combinação tenha se desprendido um produto novo" (DURKHEIM, 2007a, p. XX). Como a memória bergsoniana, o fato social é o produto de uma síntese criadora e, enquanto tal, irredutível a uma mera duplicaçáo de suas causas. O presente sensório-motor se torna lembrança que se alinha à totalidade de nossa personalidade, modificando-a, afirma Bergson. O individual se torna coletivo, sustenta Durkheim. E, em ambos os casos, há diferença qualitativa entre os termos da relação. Eles se tornam outra coisa, na passagem operada entre presente e passado, entre individual e coletivo. No mais, em ambos os casos, o efeito não pode ser localizado à contracorrente em suas causas, nos elementos que entram em sua composição. Do mesmo modo que a memória, efeito de uma síntese de momentos presentes, não pode 
ser localizada no cérebro, a consciência coletiva não pode ser localizada na multiplicidade de indivíduos de cuja síntese ela se origina - "[...] eles passam, e ela permanece." (DURKHEIM, 2007b, p. 46).

$\mathrm{O}$ todo apenas se forma pelo agrupamento das partes e esse agrupamento não se faz em um instante, por um milagre brusco [...]. Mas, na medida em que a associaçáo se constitui, ela dá nascimento a fenômenos que náo derivam diretamente dos elementos associados; e essa independência parcial é táo mais marcada quanto mais numerosos e mais poderosamente sintetizados são esses elementos. (DURKHEIM, 2010, p. 42).

Essa passagem apresenta elementos cruciais. A síntese do diverso, representada pela associação de indivíduos, é responsável não somente pela originalidade resultante, mas, igualmente, pela autonomia relativa que esse todo ganha para com as partes que participam como a matéria de sua formação. Uma vez criada, a totalidade representada pela consciência coletiva se emancipa de seus componentes, passando a residir "[...] no todo formado por sua união” (DURKHEIM, 2007a, p. XIV). Esse todo, ubíquo e impessoal (DURKHEIM, 1996), não pode ser tocado, não pode se fazer objeto de um julgamento de localização. Como a memória bergsoniana, ele é dotado de um caráter incorporal. $\mathrm{O}$ modo de ser especial que Durkheim reconhece aos fatos sociais é da mesma natureza, por conseguinte, que o modo de ser especial do espírito tal qual apresentado por Bergson: produto de uma síntese sui generis, responsável ao mesmo tempo por sua gênese quanto por sua conservação, existente e atuante sem ser, contudo, localizável: nem nas causas das quais provém, nem em parte alguma.

Há ainda outro elemento que valida o paralelo entre Bergson e Durkheim que estamos em vias de desenvolver. Trata-se da forma pela qual nossos autores reconhecem a existência de uma causalidade psíquica inconsciente. Para evitar os contrassensos que a palavra inconsciente ${ }^{6}$ apresenta, afirma Durkheim (2010, p. 31), temos de nos representar uma consciência sem eu, sem apreensão de um estado psíquico por um sujeito dado. Isso não contraria uma proposição fundamental de sua sociologia - a saber, "[...] que fenômenos se passam em nós, que são de ordem psíquica e que, no entanto, não são conhecidos do eu que nós somos". Mas contraria hábitos fundamentais

\footnotetext{
${ }^{6}$ Segundo Mucchielli (1998), a teoria durkheimiana das representaçôes coletivas é uma formalização original de um modelo de causalidade psíquica que marca presença nas ciências humanas, em finais do século XIX: aquele do inconsciente.
} 
pelos quais concebemos os limites da consciência individual. Afinal, trata-se de reconhecer que "[...] a vida representativa se estende para além de nossa consciência atual.” (DURKHEIM, 2010, p. 32).

No fundo a noção de uma representação inconsciente e aquela de uma consciência sem eu que apreende são equivalentes. Pois quando dizemos que um fato psíquico é inconsciente, dizemos somente que ele não é apreendido. Toda a questáo é saber qual expressão é melhor empregar. Do ponto de vista da imaginação, uma e outra têm o mesmo inconveniente. Não nos é mais fácil imaginar uma representaçáo sem sujeito que se representa do que uma representação sem consciência. (DURKHEIM, 2010, p. 32).

$\mathrm{Na}$ verdade, o problema se coloca àquele incapaz de compreender a imaterialidade e a ubiquidade de uma consciência que, coletiva, ocupando ao mesmo tempo todos os espaços, informando todos os sujeitos, não é localizável em nenhum local preciso (DURKHEIM, 1996). O problema se colocaria àquele que fosse incapaz de se representar uma existência representativa fora de uma consciência que a representa. $\mathrm{O}$ mesmo inconveniente Bergson encontra na representação da totalidade de nosso passado, não apenas fora do cérebro, mas também independente da ação presente.

[...] limitemo-nos a observar que nossa repugnância em conceber estados psicológicos inconscientes vem, sobretudo, do fato que tomamos a consciência como propriedade essencial dos estados psicológicos, de modo que um estado psicológico náo poderia deixar de ser consciente, pareceria, sem deixar de existir. Mas se a consciência é apenas a marca característica do presente, ou seja, do atualmente vivido, ou seja, enfim, do agente, então o que não age poderá deixar de pertencer à consciência sem deixar necessariamente de existir de alguma maneira. Em outros termos, no domínio psicológico, consciência não seria sinônimo de existência, mas somente de ação real ou eficácia imediata, e a extensão desse termo se encontrando assim limitada, teríamos menos dificuldade em nos representar um estado psicológico inconsciente, ou seja, em suma, impotente. (BERGSON, 2008c, p. 157).

As dificuldades reconhecidas por Bergson e por Durkheim, em termos da concepção de uma maneira de existir inconsciente, se assemelham ${ }^{7}$. Elas

\footnotetext{
${ }^{7}$ Do ponto de vista bergsoniano, a incapacidade em conceber estados psíquicos inconscientes se deve a uma atribuição à série das lembranças acumuladas da "[...] necessidade de conter e ser contida que apenas é verdadeira para os corpos instantaneamente percebidos no espaço.” (BERGSON, 2008c,
} 
caminham na contramão de uma visão da vida do espírito incapaz de admitir a existência de algo que, de um lado, não é presente e atuante, e que, de outro, não é localizável nos limites de uma representação individual. A consciência coletiva não encontra sua razão de ser no suporte que a contém, no indivíduo pela qual ela se realiza ou no estado mental individual no qual ela se manifesta. Da mesma maneira, o espírito ou memória bergsoniana não se confunde com os contornos adquiridos por uma percepção presente. Tanto Bergson quanto Durkheim visam a afirmar que a vida do espírito excede aquilo que uma consciência pode representar distintamente. Aquilo que é distintamente percebido deixa na sombra a real espessura do espírito, seja o espírito mnemônico bergsoniano, seja o espírito coletivo durkheimiano. Em ambos os casos, inconsciência não é sinônimo de inexistência, porém, ao contrário, de autonomia e independência, de um modo de ser especial e que se desenvolve segundo suas próprias leis.

Vimos que a admissão de um inconsciente psíquico coletivo implica o reconhecimento de uma consciência sem eu, de uma realidade que, para existir, não pressupóe uma relação entre continente e conteúdo. Durkheim nos autoriza a retirar o sujeito da ação mantendo, ao mesmo tempo, a natureza dessa ação, pois os atributos essenciais da vida do espírito se encontram presentes na hiperespiritualidade representada pela consciência coletiva. Substituamos, por conseguinte, os termos mobilizados pelo espírito individual (sensaçôes, percepçôes e acontecimentos que se tornam lembranças acumuladas) por aqueles mobilizados pelo espírito coletivo (modos de ser, de fazer e representaçóes que definem o fato psíquico individual). E nos utilizemos do instrumental bergsoniano, o qual define a ação criadora da memória como síntese que se conserva automaticamente, sem um sujeito que tenha de deliberar em torno da fusão criadora ou de sua conservação. O que retirar dessas operaçôes? A consciência coletiva durkheimiana, na qualidade de inconsciente psíquico incorporal (existente sem ser consciente, agente sem ser o traço deixado por um sujeito, liberado das exigências de uma relação entre continente e conteúdo), é fruto de um ato criador que guarda as mesmas características essenciais da atividade mnemônica apresentada por Bergson.

p. 166). Necessidade análoga coloca dificuldades, do ponto de vista de Durkheim, à concepção de representaçôes que, para existir, não têm necessidade de um sujeito que as represente. Sua existência independe de uma relação entre continente e conteúdo. Não é uma representação em ato o signo dos limites de uma existência psíquica. Pelo contrário, dessa representação em ato - ou melhor, do caráter coercitivo de algumas dentre elas - Durkheim (2007a, 2007b) retirará a prova de uma existência psíquica que é exterior ao indivíduo. 
Se nosso recurso à metafísica bergsoniana é válido ${ }^{8}$, podemos afirmar que aquilo que Durkheim julgou sociologicamente insolúvel se resolveria, caso tomássemos a consciência coletiva como uma totalidade que se produz e reproduz tal qual a memória bergsoniana.

\section{CONSIDERAÇÓES FINAIS}

Os aspectos que descrevemos da sociologia de Durkheim acabam por corroborar algo que o próprio Bergson reconheceu. Ao contrário da psicologia, a qual se constituiu em ciência sem "[...] se solidarizar com nenhum sistema filosófico”, a sociologia de Durkheim é “[...] menos fácil de isolar da filosofia propriamente dita” (BERGSON, 2011c, p. 381). Com isso, porém, não pretendemos admitir uma fundamentação metafísica das teses científicas de Durkheim. Reconhecer uma licença à metafísica para a solução de um problema sociologicamente insolúvel é coisa distinta de afirmar a existência de uma metafísica durkheimiana.

Durkheim visa a edificar uma sociologia científica, a qual aborda os fatos sociais como "coisas", "[...] tomando por princípio que ignoramos absolutamente o que eles são, e que suas propriedades características, como as causas desconhecidas das quais elas dependem", não podem ser descobertas pela "introspecção mesmo a mais atenta" (DURKHEIM, 2007a, p XI). Enquanto "coisa", objeto de conhecimento "[...] que não é naturalmente penetrável à inteligência”, o fato social apenas pode ser compreendido com a condição de o espírito "[...] sair de si mesmo, por meio de observaçóes e experimentações, passando progressivamente" dos seus "caracteres os mais exteriores" aos "menos visíveis e mais profundos." (DURKHEIM, 2007a, p XI). É possível observar quão distante essas exigências metodológicas se

\footnotetext{
${ }^{8}$ Recurso que, não à toa, chamamos acima de uma extrapolação dos serviços prestados por uma filosofia de orientação espiritualista à ciência durkheimiana dos fatos sociais. Não há evidência textual de que Durkheim tenha admitido que a metafísica da memória bergsoniana fosse capaz de elucidar aquilo que sua sociologia foi incapaz de resolver. Todavia, vimos que Durkheim deixou uma porta aberta à metafísica, bem como vimos que semelhanças são observáveis entre as concepçōes bergsoniana e durkheimiana acerca da memória individual e da relação que a consciência guarda com seu substrato cerebral. São esses elementos que autorizaram o estabelecimento da hipótese acima desenvolvida.

${ }^{9} \mathrm{O}$ mesmo pode ser enfatizado em termos das relaçôes acadêmico-institucionais na França de finais do século XIX e início do século XX. Para essa dimensão do problema da relação entre ciência e filosofia no projeto de sociologia de Durkheim, reportamos à análise que Jean-Louis Fabiani realiza das transformaçôes do campo professoral francês, entre os anos 1880 e 1914. Nesse cenário, “[...] os fundadores de ciência, que pretendiam romper com a metafísica, jamais deixaram completamente o campo filosófico." (FABIANI, 1988, p. 131).
} 
encontram de uma metafísica como a bergsoniana. Esta (longe de ser uma mera introspecção, diga-se) admite, via intuição, que há uma "[...] realidade exterior [...] imediatamente dada a nosso espirito", pois a "consciência que temos de nossa pessoa" nos introduz "[...] no interior de uma realidade sobre o modelo da qual devemos nos representar as outras" (BERGSON, 2009, p. 211, grifo do autor).

Esse gênero de acesso aos fatos Durkheim jamais admitirá: eles devem ser estudados "[...] do exterior, ou seja, como coisas" (DURKHEIM, 2007a, p. XI). Ao passo que o filósofo da duração fará da psicologia o "vestíbulo da metafísica" (RIQUIER, 2009, p. 85), autorizando-se da "existência de que somos mais certos" e que "melhor conhecemos", ou seja, "a nossa", na medida em que "[...] nos percebemos a nós mesmos interiormente, profundamente" (BERGSON, 2008e, p. 01), para discorrer acerca do material e do vital, o cientista dos fatos sociais defende uma atitude distinta. Mesmo aquilo que nos seria em certa medida interior, fatos que, sociais, não deixam de ter uma expressáo mental na consciência do sujeito informado pela sociedade, é preciso abordar com o mesmo estado de espírito em que se encontram "[...] físicos, químicos, fisiologistas, quando eles se engajam em uma região ainda inexplorada de seu domínio científico" (DURKHEIM, 2007a, p. 12). A maturidade intelectual da sociologia se encontra na dependência de uma modificação na atitude do sujeito do conhecimento diante de seu objeto: ele apenas pode ser estudado "cientificamente", com a condição de o ser "objetivamente", e não a partir da sensação de que nos movemos "[...] no meio de coisas que são imediatamente transparentes para o espírito” (DURKHEIM, 2007a, p. XII-XIII).

Não obstante o pendor cientificista de sua sociologia, Durkheim considera um problema que pertence à sociologia e que, no entanto, ela náo pode resolver. No mais, antes mesmo dessa admissão, vimos que o modo pelo qual Durkheim resolve o problema da natureza do espírito individual se encontra em consonância com a crítica filosófica às teses epifenomenistas da psicologia, crítica que ilustramos com Bergson. Dessa maneira, Durkheim recorre a certo espiritualismo para corroborar a tese que ele pretende ser a sua: o espírito não pode ser reduzido ao substrato neurofisiológico que lhe subentende. E, desse recurso, Durkheim retira fundamentos para preconizar a mesma coisa, no que diz respeito à relação da consciência coletiva ou hiperespiritualidade com seu substrato, representado pelas consciências individuais. Ou seja, o "problema do espírito" não figura na sociologia de Durkheim como um "problema exterior", tampouco "metafísico", mas como 
um "[...] desvio indispensável para abrir seu próprio domínio científico." (WORMS, 2009, p. 97). Nosso percurso mostrou que, a despeito da atitude do homem de ciência que pretende se afastar da filosofia, encontramos em Durkheim os traços de um problema com ela compartilhado, bem como resolvido de modo análogo. Poderíamos, no limite, reconhecer na sociologia de Durkheim uma coloração espiritualista.

Fomos, pois, levados a observar um Durkheim mais próximo de teses filosóficas que lhe eram contemporâneas do que nos permitiria reconhecer uma interpretação demasiado apressada de uma afirmação como esta: "Nossa regra não implica então nenhuma concepção metafísica, nenhuma especulação sobre o fundo dos seres.” (DURKHEIM, 2007a, p. XII). Essa insurgência contra a filosofia não deve mascarar, de nosso ponto de vista, os ecos que ganham na sociologia de Durkheim problemas os quais se desenham na filosofia francesa do século XIX. Segundo Worms (2009), a maneira pela qual o problema do espírito figura na sociologia de Durkheim é um aspecto característico das relaçóes entre ciência e filosofia, no referido período. Trata-se não simplesmente de duplicar uma reflexão filosófica, muito menos, no que diz respeito a Durkheim, de estabelecer uma tese metafísica, mas de "[...] criar procedimentos científicos novos” no esteio dessa reflexão (WORMS, 2009, p. 84-85). Nosso objetivo foi demonstrar alguns aspectos a partir dos quais uma atitude dessa natureza pode ser encontrada na sociologia de Durkheim.

TEIXEIRA, Rafael Henrique. Durkheim's critique of epiphenominalism in psychology and its sociological and philosophical implications. Trans/form/ação, Marília, v.39, n. 4, p.9-32, Out./Dez., 2016.

\footnotetext{
ABSTRACT: The purpose of this article is employing Durkheim's criticism of epiphenomenalism in psychology to demonstrate the way his sociological work mobilizes characteristic subjects and problems of the late nineteenth century French philosophy. Firstly we will describe Durkheim's approach to the philosophical thesis in order to point out the insufficiencies of the psychophysiology on the definition of psychic life. We proceed to present the consonance of Durkheim's point of view with the conceptions of his contemporary, Bergson. We are willing to demonstrate that Durkheim is not concerned with the mere reproduction of philosophical theses. After establishing an analogy between the individual and collective consciousness, Durkheim will take a fundamental assumption inspired by a philosophical critique of epiphenomenalism - namely, the autonomy and the relative independence of spirit toward his substrate - and extend it to their own conception of society. Finally, in accordance with Durkheim, who admits that the problem of the genesis of the collective from
} 
individual is a sociologically insoluble problem, and that its resolution is a metaphysical task, we intend to demonstrate how the spiritualistic philosophy, celebrated by Durkheim as providing great services to science, could contribute for the elucidation of this enigmatic process.

KEYWORDS: Sociology. Philosophy. Memory. Individual. Society.

\section{REFERÊNCIAS}

BERGSON, H. Essai sur les données immédiates de la conscience. 9. éd. Paris: PUF, 2007. 322 .

Le cerveau et la pensée: une illusion philosophique. In: . L'énergie spirituelle. 8. éd. Paris: PUF, 2008a. p. 191-210.

29-60.

. L'âme et le corps. In:

L'énergie spirituelle. 8. éd. Paris: PUF, 2008b. p.

Matière et mémoire. 8. éd. Paris: PUF, 2008c. 521p.

. Le effort intellectuel. In: . L'énergie spirituelle. 8. éd. Paris: PUF, 2008d. p. 153-190.

. L'évolution créatrice. 11. éd. Paris: PUF, 2008e. 693p.

. Introduction à la métaphysique. In: . La Pensée et le mouvant. 16. éd. Paris: PUF, 2009. p. 177-227.

. La philosophie française. In: . Écrits philosophiques. Paris: PUF, 2011a. p. 452-479.

. Le parallélisme psycho-physique et la métaphysique positive”. In: Écrits philosophiques. Paris: PUF, 2011b. p. 231-272.

“Bergson à V. Norström, 12 avril 1910. In: Écrits philosophiques. Paris: PUF, 2011c. p. 380-384.

BOUTROUX, E. De la contingence des lois de la nature . 2. éd. Paris: Félix Alcan. 1895. $170 \mathrm{p}$.

DURKHEIM, E. As formas elementares da vida religiosa. 4. ed. São Paulo: Martins fontes, 1996. 609p.

. Les règles de la méthode sociologique. 13. éd. Paris: PUF, 2007a. 149p.

. De la division du travail social. 7. éd. Paris: PUF, 2007b. 406p.

. Représentations individuelles et représentations collectives. In: Sociologie et Philosophie. 4. éd. Paris: PUF, 2010. p. 01-48.

. O suicídio: estudo de sociologia. 2. ed. São Paulo: Martins Fontes, 2011. 513p.

FABIANI, J-L. Les philosophes de la république. Paris: Les Éditions de Minuit, 1988. 176p. 
FEDI, L. Entre organicisme et individualisme, la concurrence des philosophies sociales en France vers 1900. In: WORMS, F. (Éd.). Le moment 1900 en philosophie. Villeneuve d'Ascq: Presses Universitaires du Septentrion, 2004. p. 362-372.

MUCCHIELLI, L. Sociologie et psychologie en France, l'appel à un territoire commun: vers une psychologie collective (1890-1940). Revue de Synthèse, Paris, v. 115, n. 3, p. 445483, jul.1994.

. La découverte du social: naissance de la sociologie en France (1870-1914). Paris: Éditions la Découverte, 1998. 572p.

RIBOT, T. Les conditions organiques de la personnalité. Revue Philosophique de la France et de L'étranger, Paris, tome 16, p. 619-642, jul/dec. 1883.

RIQUIER, C. Archéologie de Bergson: temps et métaphysique. Paris: PUF, 2009. 484p.

TAINE, H. De l'intelligence. 2. éd. Paris: Hachette, 1870. 492p.

WORMS, F. Bergson ou les deux sens de la vie. Paris: PUF, 2004. 361p. . La philosophie en France au XXe siècle: moments. Paris: Gallimard, 2009. 643p.

Recebido em 22/11/2015

Aceito em 05/03/2016 